\title{
A MODERNIZAÇÃO “EFICAZ” DA PROFISSÃO DE PROFESSOR CONFRONTADA ÀS NOVAS POLÍTICAS DE ACCOUNTABILITY
}

\author{
Romuald Normand (Université de Strasbourg - França)*
}

\section{RESUMO}

Atualmente, a reestruturação da profissão de professor tende a se inscrever em todos os lugares na Europa no que se refere ao estabelecimento de objetivos, medidas de performance ou de eficácia, mesmo se há construções diferentes de um país a outro. A eficiência e a eficácia do corpo docente devem permitir uma melhoria dos resultados dos exames e dos testes aos alunos. A Nova Gestão Pública se funda sobre os princípios da racionalidade econômica e financeira, visando a eficiência, a eficácia e se apoiando sobre organismos reguladores (ministérios e agências) que reforçam a exigência da prestação de contas (accountability). Este acoplamento entre gestão e avaliação serve para justificar o domínio da despesa pública em educação e, mais particularmente, a racionalização do custo da gestão de recursos humanos. O artigo examina, de maneira crítica, os efeitos desta gerência da performance sobre os professores da educação, mostrando como as políticas de prestação de contas se renovam por meio de seus conteúdos e instrumentos. Palavras-chave: Accountability. Nova gestão pública. Profissões. Performatividade. Política da prova.

\section{RÉSUMÉ}

\section{LA MODERNISATION “EFFICACE” DE LA PROFESSION ENSEIGNANTE CONFRONTEE AUX NOUVELLES POLITIQUES DE L'ACCOUNTABILITY}

Aujourd'hui, la restructuration de la profession enseignante tend à s'inscrire partout dans l'Europe en référence à la fixation d'objectifs, et des mesures de la performance ou de l'efficacité, même si les mises en œuvre diffèrent d'un pays à l'autre. L'efficience et l'efficacité du corps enseignant doit permettre d'améliorer les résultats aux examens et aux tests des élèves. La Nouvelle Gestion Publique se fonde sur des principes de rationalité économique et financière visant l'efficience et l'efficacité, et s'appuient sur des organismes régulateurs (ministères ou agences) qui renforcent l'exigence de rendre compte. Ce couplage entre gestion et évaluation sert à justifier la maîtrise de la dépense publique en éducation et plus particulièrement la rationalisation du coût de la gestion des ressources humaines. L'article examine de manière critique les effets de ce management de la performance sur les professions de l'éducation en montrant comment les politiques d'accountability se renouvellent dans leurs contenus et leurs instruments. Mots clés: Accountability. Nouvelle gestion publique. Professions. Performativité. Politique de la preuve.

* Doutor em Sociologia pela Escola de Estudos Superiores em Ciências Sociais (École des Hautes Etudes en Siences Sociales - EHESS), Paris, França. Professor de Sociologia da Faculdade de Ciências Sociais da Universidade de Strasbourg, Unidade de Pesquisa Mista (Faculté de sciences sociales, Unité de Recherche Mixte CNRS 7363 Société, Acteurs et Gouvernement en Education - SAGE, Unité Recherche Mixte), França. E-mail: rnormand@unistra.fr 


\section{ABSTRACT}

\section{THE "EFFECTIVE" MODERNIZATION OF THE TEACHING PROFESSION FACING NEW ACCOUNTABILITY POLICIES}

Today, the restructuring of teaching profession is becoming everywhere in Europe a common objective in implementing targets, performance and effectiveness measurements, even if there are some differences between countries. The teaching force's efficiency and effectiveness is considered as a mean to improve student scores in tests and exams. New Public Management is based on some principles of economic and financial rationality aiming efficiency and effectiveness supported by regulative organizations (ministries or agencies) which strengthen accountability requirements. This link between management and accountability is used to justify the mastery of public expenditures in education and particularly the rationalization of costs in human resources management. The paper examines critically some effects of performance management on educational professions in showing how accountability policies are renewed in their contents and instruments.

Keywords: Accountability. New public management. Professions. Performativity. Evidence-based policy.

\section{RESUMEN}

Actualmente, la reestructuración de la profesión de profesor tiende a inscribirse en todas partes en Europa en lo que se refiere al establecimiento de objetivos, medidas de rendimiento o de eficacia, incluso si hay construcciones diferentes de un país a otro. La eficiencia y la eficacia del cuerpo docente deben permitir una mejora de los resultados de los exámenes y de las pruebas a los alumnos. La nueva gestión pública se fundamenta en los principios de la racionalidad económica y financiera, buscando la eficiencia, la eficacia y apoyándose sobre organismos reguladores (ministerios y agencias) que refuerzan la exigencia de la rendición de cuentas (accountability). Este acoplamiento entre gestión y evaluación sirve para justificar el dominio del gasto público en educación $\mathrm{y}$, más particularmente, la racionalización del costo de la gestión de recursos humanos. El artículo examina, de manera crítica, los efectos de esta gerencia de la performance sobre los profesores de la educación, mostrando cómo las políticas de rendición de cuentas se renuevan a través de sus contenidos e instrumentos.

Palabras calve: Accountability. Nueva gestión pública. Profesiones. Performatividad. Política de la prueba.

\section{Introdução}

O presente artigo examina a maneira pela qual a introdução de critérios de eficácia na reestruturação e na desregulação dos sistemas educativos erige novas culturas profissionalizantes e de gestão dos atores em educação. Ainda que o processo não seja novo, e que tenha produzido inúmeras críticas, propomos uma análise das políticas de modernização observáveis no mundo, especialmente pela imposição de procedimentos centrados na performance medida como conquista em termos de ensino e aprendizado. Estas mudanças devem ser ajustadas, entre outras reformas de grande amplitude do setor público, visando conciliar as exigências de uma "economia do conhecimento" e uma reforma das organizações educativas para preparar os professores por meio 
de uma formação contínua e permanente, para uma melhor cultura de avaliação e de gestão dos resultados.

\section{Os desenvolvimentos das políticas de accountability no curso das últimas décadas}

A orientação política do accountability não é nova. Ela começou nos anos 1980-1990 nos países anglo-saxões, a partir da construção de uma política de competências de base e de prestação de contas (BALL, 2017). As críticas em relação ao baixo ní- vel e a grande autonomia acordada aos professores terminaram por considerar os docentes como "uma parte do problema", antes que esta retórica fosse retomada pelas grandes organizações internacionais, que distribuem as recomendações seguidas da publicação da pesquisa PISA (POPKEWITZ, 1998). Hoje em dia, a reestruturação da profissão de professor tende a se inscrever em todos os lugares na Europa em referência à fixação de objetivos, medidas de performance ou de eficácia, mesmo se as construções diferem de um país a outro (GUNTER et al, 2016). Estas transformações são descritas no Quadro 1 a seguir.

Quadro 1 - Les tranformations de la régulation de la profession enseignante par l'accountability

\begin{tabular}{|c|c|c|c|}
\hline $\begin{array}{l}\text { Formas de } \\
\text { regulação }\end{array}$ & $\begin{array}{c}\text { 1960-meados } \\
\text { dos anos } 1980 \\
\text { Desenvolvimento } \\
\text { de uma autonomia } \\
\text { relativa }\end{array}$ & $\begin{array}{c}\text { Anos 1980-1990 } \\
\text { Autonomia controlada } \\
\text { pelo gestor da } \\
\text { performance }\end{array}$ & $\begin{array}{c}2000 \text { em diante } \\
\text { Autonomia produtiva e } \\
\text { performatividade }\end{array}$ \\
\hline $\begin{array}{c}\text { Avaliação dos } \\
\text { professores } \\
\text { (accountability) }\end{array}$ & $\begin{array}{l}\text { Autoavaliação } \\
\text { informal. Avaliação } \\
\text { externa pelos pares. }\end{array}$ & $\begin{array}{l}\text { Autoavaliação dentro de } \\
\text { em um contexto formal } \\
\text { de Avaliação externa } \\
\text { através de diretivas } \\
\text { do gestor. Processo de } \\
\text { controle pelo gestor. }\end{array}$ & $\begin{array}{c}\text { Autoavaliação da } \\
\text { organização através de } \\
\text { um auditor de resultados } \\
\text { dos alunos em termos de } \\
\text { aprendizado. O gestor } \\
\text { controla o conjunto do } \\
\text { processo. }\end{array}$ \\
\hline $\begin{array}{l}\text { Controle da } \\
\text { eficácia dos } \\
\text { professores }\end{array}$ & $\begin{array}{c}\text { O professor trabalha } \\
\text { nas estruturas e o } \\
\text { currículo é estabelecido } \\
\text { pelos chefes do } \\
\text { estabelecimento. } \\
\text { Alguns sistemas de } \\
\text { avaliação voluntária nas } \\
\text { escolas. }\end{array}$ & $\begin{array}{c}\text { Eficácia controlada } \\
\text { pelo gestor do } \\
\text { estabelecimento. Acordos } \\
\text { locais autorizados e sem } \\
\text { sistema de remuneração } \\
\text { segundo a performance. }\end{array}$ & $\begin{array}{l}\text { Os objetivos assumidos } \\
\text { pelos professores e pelas } \\
\text { organizações são inscritos } \\
\text { no currículo nacional e } \\
\text { dentro de um contexto } \\
\text { de performance. A } \\
\text { remuneração depende do } \\
\text { alcance dos objetivos. }\end{array}$ \\
\hline $\begin{array}{c}\text { Evidência da } \\
\text { eficácia }\end{array}$ & Coleta informal. & $\begin{array}{l}\text { Qualitativa e formalizada } \\
\text { pela observação de } \\
\text { classe. }\end{array}$ & $\begin{array}{c}\text { Formalizado e } \\
\text { quantitativo sobre os } \\
\text { resultados, qualitativa no } \\
\text { que se refere às relações } \\
\text { pessoais e de classe. }\end{array}$ \\
\hline
\end{tabular}




\begin{tabular}{|c|c|c|c|}
\hline Medida da eficácia & $\begin{array}{c}\text { O significado e a } \\
\text { interpretação da } \\
\text { performance são } \\
\text { determinados pela } \\
\text { base das relações } \\
\text { profissionais e dos } \\
\text { grupos de referência. }\end{array}$ & $\begin{array}{c}\text { Objetivos de } \\
\text { desenvolvimento no } \\
\text { plano profissional } \\
\text { discutidos a partir da } \\
\text { base de uma observação } \\
\text { formal da classe. }\end{array}$ & $\begin{array}{c}\text { A performance é medida } \\
\text { através de cálculos } \\
\text { estatísticos e o valor } \\
\text { somado pelo professor } \\
\text { aos resultados dos alunos. }\end{array}$ \\
$\begin{array}{c}\text { Gestão dos alunos } \\
\text { pelos professores }\end{array}$ & $\begin{array}{c}\text { Valorização do } \\
\text { engajamento ético } \\
\text { perante o aluno. }\end{array}$ & $\begin{array}{c}\text { As crianças são clientes } \\
\text { que as escolas devem } \\
\text { atrair em razão dos } \\
\text { resultados dos alunos. }\end{array}$ & $\begin{array}{c}\text { As crianças são objetos } \\
\text { e objetivos a avaliar e } \\
\text { contabilizar. }\end{array}$ \\
\hline $\begin{array}{c}\text { Gestão dos } \\
\text { professores }\end{array}$ & $\begin{array}{c}\text { Legitimidade } \\
\text { profissional e } \\
\text { estatutária do chefe do } \\
\text { estabelecimento. }\end{array}$ & $\begin{array}{c}\text { A gestão tem um papel } \\
\text { de controle sobre o } \\
\text { conjunto do processo. }\end{array}$ & $\begin{array}{c}\text { governo e os professores, } \\
\text { e são publicamente } \\
\text { responsáveis pelas } \\
\text { performances. }\end{array}$ \\
\hline
\end{tabular}

Fonte: Ranson (2003, p. 463).

Ao longo das últimas décadas, a promoção de um gerenciamento científico neotayloriano, especialmente no uso dos planos de desenvolvimento racionais e lineares, nos quais os professores deveriam ser integrados, encontrou sua expressão dentro de uma retórica usada por uma visão de gestão na qual as noções de "equipe, de "mobilização" (empowerment), de "justeza dos objetivos a alcançar" são colocadas em correspondência com as necessidades de avaliar os professores para ajudá-los a realizar seus potenciais e melhorar a qualidade da educação.

Segundo essa concepção neoadministrativa, a avaliação conduz a uma performance e ao desenvolvimento profissional dos professores que melhor corresponderia às necessidades da escola. A eficiência e a eficácia do corpo docente devem permitir melhorar os resultados dos exames e dos testes aos alunos. Esta tendência neotayloriana é perceptível através do desenvolvimento do ciclo de gestão por performance (planificar, executar, pilotar, avaliar) combinado a um discurso sobre os recursos humanos, no qual o trabalho de ensino é ainda mais conectado aos objetivos e às novas normas a responder (GEWIRTZ, 2003). Tal dinâmica conduz a mudanças estratégicas na maneira pela qual a informação é coletada, analisada e sintetizada para motivar e melhorar o profissionalismo dos professores, encorajando-os a assumir riscos assim como ter ambições. Enquanto os professores são convidados a se engajar em um desenvolvimento profissional contínuo, as medidas de auditoria recolocam a abordagem tradicional de inspeção e a metodologia de autoavaliação se instala nos estabelecimentos.

\section{A Nova Gestão Pública na educação: processo de racionalização e de "fabricação" da performatividade}

A Nova Gestão Pública se funda sobre os princípios da racionalidade econômica e financeira, buscando a eficiência e a eficácia e se apoiando sobre os organismos reguladores (ministérios ou agências) que reforçam a exigência da prestação de contas (DUNLEAVY; HOOD, 1994). Este acoplamento entre gestão e avaliação serve para justificar o domínio da despesa pública em educação e, mais particularmente, a racionalização do custo da gestão de recursos humanos. Ele permite dar 
também uma legitimidade à descentralização dos orçamentos e à responsabilização dos educadores na escala local, endossando, por vezes, os sistemas de segurança-qualidade.

Assim, a gestão da performance não se refere somente à remuneração e ao recrutamento dos professores, mas será uma espécie de pacto que permite recompensar os professores, fazendo-os aceitar novas condições de serviço (NORMAND et al, 2018). Ela implica também em procedimentos administrativos que não estabelecem uma grande relação com os aprendizados ou o desenvolvimento da profissionalização do professor. As críticas recentes pontuaram a atual forma submissa do painel do setor público a um quebra-cabeça doutrinal que chamamos de "nova gestão pública", defendendo a ideia de uma capacidade contratual dos indivíduos a aderir aos princípios da empresa e da economia de mercado.

Como consequência, Stephen Ball descreve na Inglaterra uma espécie de "esquizofrenia" que ganhou milhares da educação entre o trabalho de equipe e a individualização, o self-management e a cooperação, o desenvolvimento profissional e a pesquisa da performance (BALL, 2003). A sociologia analisa os processos de "fabricação" pelos quais os profissionais da educação utilizam os resultados, as inspeções e as avaliações para "jogar o jogo" do profissionalismo e o engajamento para a gestão, mantendo à distância seus próprios valores para melhor se submeterem às exigências dos objetivos que são impostos interna e externamente. Soma-se o fato que tais fabricações contribuem para isolar os professores diante das demandas de performance dos gestores, privando-os de todo um ambiente colegial e impondo novos modos de controle, o que acentua a pressão sobre os indivíduos.

\section{A Nova Gestão Pública: uma gestão de recursos humanos de foco "totalizante"}

Como vimos, o modelo de gestão pela performance é incrustado em uma ideologia administrativa tornada predominante na educação, como em outros campos do setor público. Torna-se importante salientar as origens desta gestão no setor público e a maneira pela qual se tornou uma característica essencial da nova gestão pública ou da gestão dos serviços públicos durante os anos 1980 e 1990 (NEWMAN; CLARKE, 2009). A Nova Gestão Pública é, atualmente, implementada em todas as áreas do serviço público: saúde, impostos, emprego etc.

A gestão da performance constitui um elemento-chave da gestão de recursos humanos. Sua forte legitimidade repousa sobre a suposição de que se pode implantar sistemas de gestão do pessoal não importando o contexto, pois os princípios de aplicação permanecem os mesmos (THRUPP; WILMOTT, 2003). Descrito de uma forma tecnicista e universal, tal gestão postula que os problemas que a gestão deve tratar são, por essência, uma questão de apresentação, de logística ou de técnica, e que estes podem ser resolvidos pela adaptação e negociação. Esta ideologia administrativa considera que existe uma série de princípios e procedimentos que podem ser implementados segundo um modo "eficaz, eficiente e econômico", levando em conta as circunstâncias específicas e considerando que existem princípios gerais superiores, qualquer que seja a situação. Pouco reconhecimento é acordado às questões de estrutura, de poder, de conflito, e o contexto social das escolas é legado a uma invisibilidade nas análises da gestão.

Mais do que ser um discurso, a gestão da performance possui características "totalizantes". Por exemplo, os professores são apresentados como unidades de trabalho que devem ser distribuídas e geridas. É uma gestão que tende a ignorar as características estruturais dos grupos de professores, como as etnias, o sexo, a sexualidade ou o pertencimento social. Esta gestão utiliza uma linguagem universal que não leva em consideração as diferenças sociais dos professores e que, justificando-se buscar uma integração, não faz mais do que excluir alguns. Mostra-se igualmente totalizante a crença exclusiva nas noções como motivação, sucesso, performance, progressão, partindo do princípio que o motor essencial do indivíduo no trabalho são a ambição, a carreira e a remuneração. Assim, o modelo da gestão da performance deseja fazer do professor um indivíduo empreendedor, que deve provar que ele é mais eficaz comparativamente aos resultados que ele consegue obter dos seus alunos, 
ainda que ele possa se engajar no trabalho de equipe ou nas atividades de cooperação.

\section{A Nova Gestão Pública: limites culturais e profissionais}

Torna-se possível observamos por meio desta Apresentação que o modelo da gestão da performance pode provocar muitos efeitos em diferentes níveis do sistema educativo: nos professores, na instituição escolar e também na sociedade. Este modelo tende a negar a importância das fronteiras e das interconexões entre todos os níveis, considerando que não existem tensões ou dissensões entre elas (HALL; GUNTER; BRAGG, 2013). Contudo, uma análise dos efeitos da gestão deve levar em conta diferentes dimensões: aprendizagem, ensino e a pedagogia, a equidade, a justiça social e as perspectivas políticas que desenham tal modelo, a variedade das visões profissionais e sindicais que se unem, as diferenças entre um ponto de vista administrativo, técnico ou economicista. Algumas destas dimensões são, contudo, amplamente ignoradas pelos promotores de tal modelo.

Outros comentadores têm pontuado também as dificuldades complexas ignoradas por essa forma de gestão ao associar o sistema de remuneração à medida de performance (BALL, 1993). À luz destas críticas, pode-se demandar se esse sistema de remuneração altamente sofisticado não é simplesmente um meio pelo qual o governo reestrutura o modo de pagamento dos professores fazendo economia do orçamento da educação. As críticas nasceram da concepção subjacente que presidia tal sistema, em especial as motivações dos professores e aquilo que os levam a melhorar. No longo prazo, muitos acreditam que esse sistema não desmotiva a maioria dos professores, que não conhecerão um aumento de suas remunerações, a qual será aproveitada somente por alguns, sem contar as divisões e os conflitos que poderão nascer de tal dispositivo. Da mesma forma, ainda que a motivação no trabalho não seja somente o dinheiro, mas também um engajamento junto aos alunos, os opositores de tal modelo salientam o fato de ele não considerar importantes consequências no interior das escolas sobre o corpo docente, cuja cultura de cooperação e de trabalho em equipe podem sofrer danos.
Da mesma forma, a construção, a forma e o conteúdo das normas profissionais em educação constitui um imenso sujeito de debate (HEXTALL; MAHONY, 2013). Definir aquilo que conta como resultado, achar os indícios que permitem medir os resultados e desenvolver meios para avaliar o alcance dos objetivos constituem uma outra dificuldade que não pode ser resolvida por uma simples prescrição visando resolver o problema. As questões sobre o sentido a ser dado a essas avaliações convencionais permanecem para além do simples controle da escola ou dos professores. Cultural e socialmente, as normas destinam-se a toda uma série de questões sobre a ideologia dos padrões e valores ou princípios que operam em nível individual ou mais coletivo do ensino (MENTER; MAHONY; HEXTALL, 2004). Em todos os casos, estes padrões constroem um mundo onde os indivíduos devem agir, mas também onde sobrevive a resistência ou o conflito, a dominação ou a exclusão. Uma das razões pelas quais a gestão não participa deste debate refere-se à sua clausura em um tecnicismo das medidas de avaliação, o que não impede que esses padrões tenham um poder estruturante sobre as práticas, obrigando a serem eficazes nas relações em diferentes níveis e ajustando os indivíduos a se conformarem com os princípios e procedimentos que possuem uma margem de ação e autonomia já determinada.

As preocupações nasceram do fato de que esse novo sistema de gestão pela performance é injusto. Se podemos pensar que "o salário é proporcional ao trabalho e ao mérito", a aplicação prática deste princípio expõe um problema. Por exemplo, a despeito da aparente transparência da avaliação dos professores, a interpretação dos resultados é objeto de um julgamento ou de uma interpretação em parte ligada às necessidades da escola e dos talentos percebidos do professor em questão, mas também em razão das situações pedagógicas (CROOKS, 2011). Da mesma maneira, foi demonstrado que aqueles que têm mais chance de sucesso são aqueles que já desenvolveram as competências necessárias. Enfim, se deixamos de lado os excessos do favoritismo ou do clientelismo produzido por tal modelo, certos professores, tendo experimentado a remunerações segundo a performance, consideram que a ligação não parece também automática e que subsistem 
práticas discriminatórias quando a avaliação não é atravessada por uma elevada subjetividade do gestor (MAHONY; MENTER; HEXTALL, 2004).

\section{A instrumentalização das práticas pedagógicas segundo a lógica da accountability}

As práticas das pedagogias não escapam a essa instrumentalização pela performance (WOODS; POLLARD, 2017). Os professores, como os comerciantes, são julgados segundo a maneira pela qual eles se conformam às normas fixadas pelos organismos reguladores e sua credibilidade ao sistema (WEBB, 2006). A autonomia, a reflexão, a criatividade e o engajamento são valorizados unicamente se eles contribuem para a produtividade. Da mesma maneira, os métodos pedagógicos não são escolhidos em razão do desenvolvimento das capacidades de autonomia, reflexão, crítica dos alunos. Elas são mobilizadas quando podem maximizar a performance da escola e participar de uma boa avaliação dos resultados da escola. O imperativo consiste em medir e melhorar os testes segundo a pontuação, o que contribui para uma redução importante dos conteúdos ensinados.

A visão oficial do "bom ensino" destaca os resultados a obter mais que o processo, segundo uma abordagem utilitarista e didática centrada nos testes. $\mathrm{O}$ modelo da pedagogia hierárquica segundo uma transmissão está em oposição direta às concepções dos professores e do ensino que, frequentemente, implementam métodos pedagógicos mais globais e centrados nas crianças. Contudo, a visão sustentada pela qualidade colide com a abordagem desenvolvida por outros docentes desde os anos 1970, que se engajaram em um importante trabalho de adaptação do currículo com os alunos estrangeiros à cultura etnocêntrica do ensino nacional (DANIELS, 1995).

\section{Os desenvolvimentos recentes da accountability}

Apesar das críticas e limites, os simpatizantes da avaliação, especialistas e tomadores de decisões políticas não têm, contudo, renunciado aos desenvolvimentos da accountability, que coloca a avaliação no centro dos sistemas e das políticas educativas. Atualmente, eles reivindicam, entretanto, uma prestação de contas mais leve, em especial no que diz respeito ao desenvolvimento das autoavaliações (HOOGE; BURNS; WILKOSZEWSKI, 2012). Outra tendência, fortemente marcada pelo desenvolvimento de tecnologias digitais, refere-se à melhoria da traçabilidade dos resultados dos alunos e dos professores, introduzindo medidas mais finas e em tempo real do progresso dos alunos, demandando aos professores que tragam uma prova da eficácia e implementando boas práticas resultantes de pesquisas (SLAVIN, 2002). Guias práticos e soluções-chave são propostos para serem mais eficazes nas suas práticas pedagógicas.

"O que é que funciona?" é a palavra de ordem dos promotores da política da evidência. Ou seja, identificar métodos pedagógicos que sejam eficazes e que respondam aos padrões que devem ser alcançados pelos professores em suas disciplinas (NORMAND, 2006). Identificar os métodos pedagógicos eficazes torna-se, assim, o contributo da pesquisa em educação. Contudo, não significa que o tipo de pesquisa é livre de imposições. Tal tipo deve fornecer resultados "neutros" e "precisos", e que sejam capazes de fazer um levantamento sistemático de uma massa importante de dados. Ou seja, que apresentem todas as garantias de "rigor" e de objetividade para provar as "boas práticas" e divulgá-las. É neste ponto que se encontra a qualidade da pesquisa, a qual passa por uma renovação das condições de administração das evidências.

Todas essas técnicas vêm de um mundo médico onde elas servem aos estudos clínicos. Temos, assim, uma hierarquia dos modos de administração das evidências e dos procedimentos (NORMAND, 2016): as metanálises, as revisões sistemáticas da literatura, os ensaios randomizados, até o acompanhamento de coortes, estudos de caso com ou sem controle para concluir com a opinião dos especialistas. Alguns pesquisadores anglo-saxões salientam que se trata de um modelo de engenharia que se impõe na pesquisa em educação e que considera que a pesquisa deve, como nas ciências naturais, mostrar soluções técnicas imediatamente aplicáveis. A divulgação das "boas práticas" deve oferecer ao professor soluções-chave para melhorar sua pedagogia. 


\section{Uma crítica da política das provas}

As críticas nasceram contra essa orientação das relações entre pesquisa e prática (HAMMERSLEY, 2007). O British Educational Research Journal endossa esses debates e argumentos, sendo um de seus porta-vozes Martin Hammersley, que respondeu, ponto a ponto, a David Hargreaves consagrando um livro sobre o tema. $\mathrm{O}$ autor apresentou três argumentos na sua resposta.

O primeiro diz respeito ao monismo metodológico que é introduzido por essas novas formas de administração da prova. Na verdade, parece difícil reduzir a complexidade social dos aprendizados a uma medida e a um tratamento padronizado, considerando a situação pedagógica como uma situação quase experimental.

O segundo refere-se à concepção simplista, segundo a qual as práticas pedagógicas poderiam aplicar as técnicas ou as regras editadas com base nos resultados de uma pesquisa. Na verdade, a pedagogia é, inicialmente, uma prática antes de ser uma técnica e clama por uma diversidade de julgamentos em situação: não se pode definir as regras pré-estabelecidas e não se pode operacionalizar com base em resultados mensuráveis.

Enfim, a inspiração vinda do mundo médico parece muito pouco apropriada para o mundo da educação. Inicialmente, na educação existe muito menos diferenças entre pesquisadores e médicos, ao contrário da medicina. No mais, algumas das pesquisas em medicina são conduzidas em laboratórios (sem ajuda de clínicos) e, mesmo em medicina, como mostrado por Howard Becker, o clínico tem mais confiança em sua instituição e em seu círculo de referência que na mobilização de saberes abstratos (BECKER, 1996).

\section{Uma compreensão errônea das relações entre teoria e prática}

Essa política tem como hipótese implícita que os pesquisadores não têm, intrinsecamente, uma concepção do bem em comum e que eles são maduros por seus próprios interesses e estratégias. $\mathrm{Na}$ verdade, a pesquisa, porque ela é organizada em comunidades de práticas ou em "comunidades epistêmicas", participa, necessariamente da defi- nição de um sentido do correto que se passa muito bem como prescrição, códigos de conduta, guias metodológicos de "boas práticas" ou de normas de qualidade. Esta falha em considerar os julgamentos e afinidades entre pesquisadores, em nome do controle da eficácia e da qualidade da pesquisa, pode minar a organização comunitária, entretanto indispensável ao trabalho científico.

É o que exprime Michael Polanyi (2009) em seu livro La Dimension Tacite (A dimensão tácita). Um pesquisador das "ciências duras" que passou sua vida a refletir sobre as condições sociais e epistemológicas do trabalho científico. O conhecimento tácito é uma parte incontornável do trabalho científico e desejar torná-lo destacado e objetivo constitui um erro desastroso: a sequência de uma descoberta científica é guiada pelo sentimento de uma realidade escondida de onde os indícios e as manifestações não são ainda revelados. O procedimento que confirma os maiores progressos de uma disciplina científica ergue-se de um trabalho de coordenação e de ajustamento mútuo entre pesquisadores.

Esse princípio do controle mútuo faz que cada pesquisador exerça um controle próximo sobre os vizinhos e outros membros da comunidade científica, não havendo necessidade de um controle externo exercido de forma sistemática. A intenção "universal", este engajamento exploratório do pesquisador para tirar a convicção de seus colegas, assim que a tomada de riscos a ela associada são essenciais para o avanço da sua disciplina. Em outras palavras, não é preciso de regras muito coercitivas que limitem a imaginação e a criatividade.

Se levamos em conta esses diferentes elementos, uma conclusão se impõe: não podemos separar os pesquisadores de uma definição do sentido do que é correto, e este sentido deve estar em primeiro lugar, pois constitui o horizonte do trabalho científico. Outra crítica é possível de ser encontrada em Isabelle Stengers (2013), quando a autora aborda as questões pedagógicas. A autora coloca a questão: "O que faz uma classe evoluir?" (STENGERS, 2013, p. 113). Sua resposta é: um professor que consiga transmitir um saber aos seus alunos. Essa autora salienta também que tais questões não encontram respostas nos números, pois eles referem-se ao conjunto dos dispositivos 
de formação, de "reciclagem", de controle, que escraviza o professor ou que o apóia. Um pouco mais adiante, ela considera que aprender a ler não tem nada de normal e que não se pode fazer economia no aprendizado das circunstâncias afetivas, relacionais, culturais e sociais, que faz com que a pedagogia não alcance jamais o estatuto que certos querem dar: de uma disciplina objetiva que encontra sua glória no fato de ultrapassar a arte atravessada pela subjetividade do professor:

Se um resultado científico pretende ser interessante ou pertinente para os outros que não sejam cientistas, ele deve, por definição, interditar de chamar a autoridade da prova, que tem por correlato a incompetência dos não cientistas, e deve encontrar os meios de interessar ativamente estes outros, ou seja, criar com eles um elo que possa ser discutido, negociado, avaliado. Estas são as apostas mínimas de uma cultura de conhecimento científico que não a torna um instrumento de poder, diferenciando aqueles que estão interessados e aqueles que são solicitados a submissão, confiança cega, fascinação com progresso e a verdade. (STENGERS, 2013, p. 114).

\section{Os professores considerados como trabalhadores sociais}

Os professores são, de mais a mais, considerados não somente como educadores, mas também como trabalhadores sociais. As questões de inclusão social (ou de educação inclusiva), de desistência e abandono da escolarização, de domínio de competências de base estão no centro da vida profissional quotidiana. Para além do ensino, eles devem levar em consideração a inclusão, a orientação e o aprendizado dos alunos. Além disso, eles são demandados a trazer as evidências do progresso e melhorias das competências dos alunos a fim de satisfazer as exigências crescentes e intrusivas do sistema de prestação de contas. O que se mostra novo é a forma como os sistemas educativos são capazes de fornecer as evidências, o que deve acelerar no futuro. Não se trata do Estado Avaliador em si mesmo, mas de um novo regime de obrigações e prestação de contas, menos exógeno, mais endógeno e ancorado nas organizações e práticas, dando a possibilidade de seguir os indivíduos, os professores e alunos.
Dois movimentos explicam essa mudança.

O primeiro deles é o desenvolvimento de mecanismos de segurança e qualidade que forçam os indivíduos a satisfazerem as exigências dos protocolos e procedimentos decididos pelos outros (hierarquia, inspeção etc.). Os professores devem seguir planos estritos e provar que eles são eficazes respeitando as regras e as prescrições: a tecnologia mais corrente é a abordagem da autoavaliação das escolas, que é desenvolvida para forçar as equipes de professores a serem responsabilizadas com relação a eles mesmos e obter informações ou dados para demonstrar uma melhoria da escola.

O segundo é o desenvolvimento de dispositivos fundado em evidências que são extraídas das revisões sistemáticas e das metanálises que pretendem demonstrar a eficácia das práticas pedagógicas, por exemplo, nos âmbitos da numeracia (capacidade de utilizar, aplicar, interpretar, comunicar, criar e criticar informações e ideias matemáticas na vida real) e da literacia (aptidão a compreender e utilizar informações escritas) que são empacotadas nos guias práticos, protocolos, manuais ou check list dos médicos. Estes dispositivos, "o que funciona", são considerados como bons recursos para mudar as práticas do professor e torná-lo mais eficaz.

\section{Os professores: de clínicos reflexivos a "replicadores"}

Todas essas tecnologias são mais intrusivas na classe e tornam o professor um preceptor de dispositivos e scripts elaborados previamente em uma espécie de compromisso entre princípios behavioristas e visões de aprendizado inspiradas pelos neurocientistas e as ciências cognitivas (BIESTA, 2007). Esse autor postulou que o professor é um clínico reflexivo capaz de estabelecer os elos entre os resultados da pesquisa, o ensino e as situações de aprendizagem a fim de ser performativo e de ajustar todas as circunstâncias às características dos alunos. Para além dos recursos, esta ideia questiona a possibilidade de fazer do professor uma espécie de cientista cognitivo dentro da classe tornada um lugar de experimentações, tal como um laboratório para testar diferentes soluções - uma cópia perfeita do médico no campo da saúde, que utiliza os dados da pesquisa fundada sobre evidências para testar 
medicamentos nos pacientes sob condições controladas. Certos sociólogos, como Hammersley ou Biesta, remarcam que é inapropriado estabelecer similitudes entre os médicos e os professores. As práticas pedagógicas não têm nada a ver com as práticas médicas. Deve-se dizer que a traçabilidade é reforçada pelo desenvolvimento de tecnologias digitais e, no futuro, com o progresso dos big data e da inteligência artificial, este movimento poderá estender-se com possibilidades de seguir as práticas de ensino em tempo real, como já é o caso em hospitais com enfermeiros que informam regularmente suas ações junto aos doentes e que digitam os dados nos computadores para informar sobre o cuidado e a evolução das patologias (TIMMERMANS; KOLKER, 2004). Se lemos os documentos da OCDE ou da Comissão Europeia e outros publicados após a pesquisa TALIS, todas essas mudanças produzem efeitos sobre a definição dos conhecimentos e competências dos professores, a forma pela qual eles são avaliados, pagos e reconhecidos em suas carreiras.

\section{Considerações finais}

Algumas reflexões sobre as desigualdades que são reforçadas pela Nova Gestão Pública e a $a c$ countability (prestação de contas) na educação: elas não interrogam apenas os critérios de redistribuição de recursos no interior do sistema educativo, mas também os princípios de justiça aos quais se referem as pessoas para agir e viver juntas.

As questões da redistribuição são, atualmente, percebidas em termos de equidade (e não mais em termos de igualdade), segundo os princípios de Rawls, que devem determinar os direitos e os deveres dos indivíduos e determinar uma nova distribuição de vantagens (CRAHAY, 2013). Na verdade, esta justiça distributiva, tal qual implementada, institui procedimentos e relações que insistem na responsabilidade dos atores e na necessidade que eles têm de prestar contas. É uma concepção que considera que todos os indivíduos têm a mesma capacidade de agir e criar oportunidades.

De fato, as condições de escolarização são implementadas segundo um orçamento público limitado e redistribuído em razão dos objetivos de performance, a partir dos princípios de livre escolha das famílias e da concorrência entre estabelecimentos. Mesmo um suplemento de recursos limitado para as escolas em dificuldade ou julgadas prioritárias não chega a interromper o processo de segregação e diferenciação produzida pelo mercado (KOZOL, 2012). Na verdade, a melhoria de uma escola se faz em detrimento de sua vizinha, operando uma redistribuição dos alunos, porém sem remediar as causas profundas do fracasso escolar.

Além disso, o mercado e as práticas administrativas e de gestão tendem a concentrar o trabalho dos professores em alunos que apresentam um nível mais elevado do que naqueles que têm maiores dificuldades, pois estes estão confinados à melhoria das suas competências básicas e sobre um currículo muito menos rico do que aquele ensinado ao aluno de classe média e superior (WASLANDER; THRUPP, 1995). Enfim, a atribuição de fundos se faz, de mais a mais, segundo uma base contratual e uma qualidade da oferta. Não é garantido que os recursos sejam atribuídos em definitivo para aqueles que têm mais necessidades, especialmente porque empresas privadas ou associações motivadas por lucro ou proselitismo relutam em gastar dinheiro com os menos motivados e mais necessitados.

Nos estabelecimentos, é possível remarcar a permanência das injustiças produzidas pelo mercado e pela seleção escolar. O tratamento dos alunos como mercadoria, aceitos ou rejeitados em razão do que eles trazem para a escola, emerge de uma forma de exploração próxima daquela desenvolvida nos primeiros tempos do capitalismo. A diferenciação entre escolas cria marginalização e empobrecimento relativo ou possivelmente guetos que fazem sofrer alunos e professores (TOMLINSON, 1997). Sem contar a humilhação, estigmatização, violência, racismo, que são reforçados, especialmente, pela pressão da busca pela performance. A lógica da Nova Gestão Pública e da accoutability ditam o ritmo da gestão das escolas segundo interesses de grupos comunitários ou de pais de alunos que são, de mais a mais, excluídos e marginalizados. Além disso, esta concepção da participação dos pais dos alunos se baseia em uma concepção limitada de seus papéis na escola, com uma exigência de conformidade a uma lógica contratual para os serviços ofertados e repressiva do comportamento dos alunos. Podemos dizer, então, que esta polí- 
tica, buscando organizar uma passagem de uma igualdade de oportunidades a uma igualdade de resultados, não reduz, entretanto, as formas de injustiça na escola.

\section{REFERÊNCIAS}

BALL, S. J. Education policy, power relations and teachers' work. British Journal of Educational Studies, v. 41, n. 2, p. 106-121, 1993. 2003. . The teacher's soul and the terrors of performativity. Journal of Education Policy, v. 18, n. 2, p. 215-228,

The education debate. Bristol, UK: Policy Press, 2017.

BECKER, H. S. The epistemology of qualitative research. In: JESSOR, R.; COLBY, A.; SHWEDER, R. (Ed.). Ethnography and human development: context and meaning in social inquiry. Chicago: University of Chicago Press, 1996. p. 53-71.

BIESTA, G. Why "what works" won't work: evidence-based practice and the democratic deficit in educational research. Educational Theory, v. 57, n. 1, p. 1-22, 2007.

CRAHAY, M. (Ed.). L'école peut-elle être juste et efficace? De l'égalité des chances à l'égalité des acquis. Bruxelles: De Boeck Supérieur, 2013.

CROOKS, Terry. Assessment for learning in the accountability era: New Zealand. Studies in Educational Evaluation, v. 37, n. 1, p. 71-77, 2011.

DANIELS, H. Pedagogic practices, tacit knowledge and discursive discrimination: Bernstein and post-Vygotskian research. British Journal of Sociology of Education, v. 16, n. 4, p. 517-531, 1995.

DUNLEAVY, P.; HOOD, C. From old public administration to new public management. Public Money \& Management, v. 14, n. 3, p. 9-16, 1994.

GEWIRTZ, S. The managerial school: post-welfarism and social justice in education. London: Routledge, 2003.

GUNTER, H. M. Et al. (Ed.). New public management and the reform of education: European lessons for policy and practice. London: Routledge, 2016.

HALL, D.; GUNTER, H.; BRAGG, J. Leadership, new public management and the re-modelling and regulation of teacher identities. International Journal of Leadership in Education, v. 16, n. 2, p. 173-190, 2013.

HAMMERSLEY, M. (Ed.). Educational research and evidence-based practice. New York: Sage, 2007.

HEXTALL, I.; MAHONY, P. Reconstructing teaching: standards, performance and accountability. London: Routledge, 2013.

HOOGE, E.; BURNS, T.; WILKOSZEWSKI, H. Looking beyond the numbers: stakeholders and multiple school accountability. OECD Publishing, 2012. (OECD Education Working Papers, $\mathrm{n}^{\mathrm{o}}$ 85). Disponível em: <http://dx.doi. org/10.1787/5k91dl7ct6q6-en>. Acesso em: 15 mar. 2018.

KOZOL, J. Savage inequalities: children in America's schools. Portland, OR: Broadway Books, 2012.

MAHONY, P.; MENTER, I.; HEXTALL, I. The emotional impact of performance-related pay on teachers in England. British Educational Research Journal, v. 30, n. 3, p. 435-456, 2004.

MENTER, I.; MAHONY, P.; HEXTALL, I. Ne'er the twain shall meet?: modernizing the teaching profession in Scotland and England. Journal of Education Policy, v. 19, n. 2, p. 195-214, 2004.

NEWMAN, J.; CLARKE, J. Publics, politics and power: remaking the public in public services. New York: Sage, 2009.

NORMAND, R. Les qualités de la recherche ou les enjeux du travail de la preuve en éducation. Éducation et Sociétés, n. 2, p. 73-91, 2006.

. 'What works?': from health to education, the shaping of the European policy of evidence. In: TRIMMER, $\overline{\mathrm{K} .}$ (Ed.). Political pressures on educational and social research. Routledge, 2016. p. 39-54. 
NORMAND, R. Et al. (Ed.). Education policies and the restructuring of the educational profession: global and comparative perspectives. Singapour: Springer, 2018.

POLANYI, M. The tacit dimension. Chicago: University of Chicago Press, 2009.

POPKEWITZ, T. Struggling for the soul: the politics of schooling and the construction of the teacher. New York: Teachers College Press, 1998.

RANSON, S. Public accountability in the age of neo-liberal governance. Journal of Education Policy, v. 18, n. 5, p. 459-480, 2003.

SLAVIN, R. E. Evidence-based education policies: Transforming educational practice and research. Educational Researcher, v. 31, n. 7, p. 15-21, 2002.

STENGERS, I. Sciences et pouvoirs: la démocratie face à la technoscience. Paris: La Découverte, 2013.

THRUPP, M.; WILLMOTT, R. Educational management in managerialist times. London: McGraw-Hill Education, 2003.

TIMMERMANS, S.; KOLKER, E. S. Evidence-based medicine and the reconfiguration of medical knowledge. Journal of Health and Social Behavior, n. 45, p. 177-193, 2004.

TOMLINSON, S. Diversity, choice and ethnicity: the effects of educational markets on ethnic minorities. Oxford Review of Education, v. 23, n. 1, p. 63-76, 1997.

WASLANDER, S.; THRUPP, M. Choice, competition and segregation: an empirical analysis of a New Zealand secondary school market, 1990-93. Journal of Education Policy, v. 10, n. 1, p. 1-26, 1995.

WEBB, P. T. The choreography of accountability. Journal of Education Policy, v. 21, n. 2, p. 201-214, 2006.

WOODS, P.; POLLARD, A. Sociology and teaching: a new challenge for the sociology of education. London: Routledge, 2017. 